\title{
Designing Solutions by a Student Centred Approach: Integration of Chemical Process Simulation with Statistical Tools to Improve Distillation Systems
}

\author{
https://doi.org/10.3991/ijep.v7i3.6795 \\ Isabel M. João( $\left.{ }^{\varpi}\right)$, João M. Silva \\ Instituto Politécnico de Lisboa, Portugal \\ Universidade de Lisboa, Portugal \\ ijoao@deq.isel.ipl.pt
}

\begin{abstract}
Projects thematically focused on simulation and statistical techniques for designing and optimizing chemical processes can be helpful in chemical engineering education in order to meet the needs of engineers. We argue for the relevance of the projects to improve a student centred approach and boost higher order thinking skills. This paper addresses the use of Aspen HYSYS by Portuguese chemical engineering master students to model distillation systems together with statistical experimental design techniques in order to optimize the systems highlighting the value of applying problem specific knowledge, simulation tools and sound statistical techniques. The paper summarizes the work developed by the students in order to model steady-state processes, dynamic processes and optimize the distillation systems emphasizing the benefits of the simulation tools and statistical techniques in helping the students learn how to learn. Students strengthened their domain specific knowledge and became motivated to rethink and improve chemical processes in their future chemical engineering profession. We discuss the main advantages of the methodology from the students' and teachers perspective.
\end{abstract}

Keywords-Active learning, Aspen HYSYS, Distillation, Factorial design, Higher order thinking skills, Problem solving.

\section{Introduction}

Engineers have the distinctive role of solving economic, environmental, and societal problems through the use of machines, devices, systems, materials and processes. The impact that chemical processes have on the environment and on the economy are of growing concern to the public, the chemical industries, and regulatory agencies.

Chemical engineering students must develop skills with the goal of designing, operating, optimizing and maintaining chemical processes in such a way that they are valuable to society, environmental benign and economically viable [1,2]. Students need to understand the design and operation of chemical processes, how changes in operations and in the environment will affect outcomes, and the actions needed to improve process performance and increase sustainability. 
Separation is one of the fundamental processes in chemical engineering and most chemical processes involve separation. Therefore, due to their popularity in the chemical process industries, looking at the design and optimization of separation systems is very important [3]. Distillation is the main separation process used in chemical industries for separation of liquid mixtures due to its versatility and ability to large-scale production. Distillation columns are the most commonly used separation units in a refinery and generally in petrochemical and chemical industries [4]. However, distillation is a highly energy intensive process which can make operating costs a concern and also, the environmental impact of such highly energy intensive process a key issue. One of the current and future challenges is to study alternatives in terms of configuration and design of distillation structures that allows improving the efficiency of the process and reducing the energy consumption in order to meet the demands of the energy conscious society [5].

The teaching in a chemical engineering course needs to reflect the challenges that the chemical engineers will face in industry. The final project of a second cycle degree can be an opportunity to instigate the students' way of thinking from the role of being a student to an engineer's thinking applying known scientific concepts for practical solutions and equipping students with the skills they will need to adapt to change.

In this paper we explore the use of Aspen HYSYS to model the distillation systems and statistical design of experiments (DOE) in order to improve the systems. Improving the systems is not straightforward because the columns may have many different configurations with diverse operating objectives. These leads to several operational degrees of freedom and distinct dynamic behaviors making it difficult to optimize and control, reason why the optimal configuration of distillation systems is a major problem in the design of chemical processes [6].

In two different projects, a case study reported in the literature was presented to the students. The problems selected from literature are complex and require some time and effort to implement. Moreover, they have a focus on novel distillation concepts (i.e. from the students' perspective) with the goal of meeting the demands of a more sustainable modern society, focusing in the reduction of costs improving ecoefficiency.

The idea is to use a case study reported in the literature as a starting point. This can be a very challenging learner based teaching method bringing new insights into the problems allowing students to explore new issues in an active way providing the opportunity for the development of key skills such as problem solving in real world situations. In the next section we focus on the relevance of the projects to improve a student centred approach. Section 3 presents the procedure for integrating Design of Experiments and Chemical Process Simulation to improve distillation systems. Section 4 presents two projects from a Portuguese chemical engineering master course. The projects were developed according to the procedure described in the previous section. The evaluation of the projects is presented in section 5 as well as the impact on students' learning. The paper concludes with the main advantages of the methodology from the students' point of view as well as some insights from the teachers' perspective. 


\section{Fostering student centered approach to learning with chemical engineering projects}

After graduate second cycle degree a chemical engineer should be able to learn on his/her own and have an understanding of the impact of engineering solutions in an economic, environmental, and societal context. One effective way to have students learn how to learn is to have students involved in projects which usually require significant faculty time reason why the master project final work is by no doubt very useful to simulate what engineers do in practice.

The Accreditation Board for Engineering and Technology (ABET) as well as other Accrediting bodies such as the European Accreditation of Engineering Programs (EUR-ACE), all agree that design is an essential element of graduate outcomes for an engineering program. The students must have the ability to design and conduct experiments as well as analyze and interpret data, the ability to design systems and processes that meet the desired needs, among others [7].

In the master project students need to do a variety of tasks by themselves and must be engaged with the project in order to be successful. The teacher that is coaching the student must place the responsibility for learning in the shoulders of the student and so the focus should be on what the student do and what the teacher want him/her to accomplish. The teacher will provide the necessary resources, guidance and instruction to the students as they simultaneously develop content knowledge and problemsolving skills. The learning is highly student centered and carried out with the teacher being more of a 'guide' than a formal teacher.

Placing the students in the centre of the learning process is a very enriching learning model [8]. Lambert and McCombs in 1998 [9] and Bransford et al. in 1999 [10] have published books with relevant information about the superiority of student centred and active learning approaches when compared to a conventional teacher centred approach. In a student-centred approach the teacher provide the students with an opportunity to learn independently and coaches the students with the skills they need to do so effectively. Handelsman et al. [11] stated that engaging students in discovery and scientific process improves learning and knowledge retention. Some studies allow concluding that in an active learning environment students' get much greater conceptual understanding, more independence, and greater confidence [12].

The spirit of student-centered learning is also fully reflected in the Engineering Criteria of the Accreditation Board for Engineering and Technology (ABET), whose the approach focuses on learning outcome not on teaching input [13]. Also the Association for Computing Machinery (ACM), and the Institute of Electrical and Electronics Engineers (IEEE), just to refer a few give emphasis to the need to move towards a learner-centred, and technology enhanced learning approaches.

Educational psychologists classify learning objectives into three domains: cognitive (knowledge, mental skills, processing of information), affective (attitudes and feelings) and psychomotor (manipulative or physical skills). The most prevailing in the cognitive domain is the so-called Bloom taxonomy first published in 1956 [14].

The project contributes to improve the student independency in learning and students acquire knowledge from a variety of sources and subject to their own critical 
evaluation having the opportunity to improve higher order thinking skills. By a student centred approach the students identify the design problem, organize the ideas and develop some representations of the problem (i.e. analyze), and also choose the working conditions, the course of action, testing designs (i.e. evaluate) and design and optimize solutions (i.e. create). According to fig. 1 the student learning cognitive domain relates to the capacity to think or one's mental skills as originally defined by Bloom et al. [14] and revised by Anderson et al. [15]. The final project will encourage higher order thinking and will foster deep conceptual understanding because the strategy is to encourage students to think and to learn by thinking.

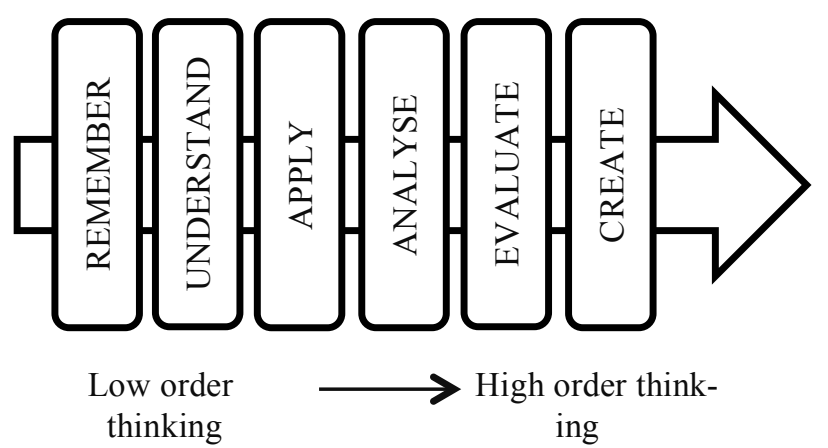

Fig. 1. A revision of Bloom's taxonomy for the cognitive domain, adapted from [15].

The role of the teacher in the master final project is more to act as a facilitator creating and managing tasks that will empower student centred learning. The role of the teacher is crucial to involve and motivate students to learn on their own, to use initiative, and to test out and apply what they have learnt.

\section{$3 \quad$ Student centered approach supported by computer simulation packages and statistical tools}

Recent proliferation in computer simulation and modelling makes it simple to use computer aided learning into teaching practices at chemical engineering. According to Glassey et al. [16] computer aided learning packages can be useful tools in supporting the development of important professional attributes as they enable students to explore and gain experience of new software environments in subject-specific context. The many advantages of chemical process simulation software makes it particularly appropriate to support student centred learning. Chemical process simulators can facilitate experimentation in real world settings. The Aspen HYSYS software aids students in learning how to use a chemical process simulator and how a process simulator is able to model quite a lot of chemical process units. The use of statistical tools along with chemical simulation packages allows to closely relating statistics as a scientific tool for solving real world problems. A review of the literature in statistical education shows that students may learn more readily with a student centred approach 
as compared to the traditional passive lecturing style [17-19]. Some authors realized that students sometimes develop misconceptions while studying statistics and so it is important that students might be confronted with their erroneous thoughts to remedy such misconceptions [20,21].

The use of chemical process simulation software is very important to optimize chemical processes in industry and, in the specific case of distillation, enables a simple and quick conceptual design of distillation structures in order to make separations of chemical mixtures.

It is of utmost importance that chemical engineering students known how to use simulation software to the rapid conceptual design of distillation schemes for the separation of chemical mixtures. The students are engaged to use software like Aspen HYSYS in a problem based learning environment to assess the limits of feasible separations for individual columns and also to design and operate advanced distillation structures for the separation of mixtures with non-ideal vapour-liquid equilibrium. The students should also understand the dual perspectives of steady state simulation and also dynamic simulation. It is worth to mention that traditional distillation design textbooks have focused predominantly on the steady state design and economics aspects of distillation. However, it is also desirable that the students learn how to deal with such issues as dynamic simulation in face of disturbances in order to develop effective control structures [22].

The design of experiments (DOE) is a strategy of planning, conducting, analysing, and interpreting experiments, in order to take valid conclusions effectively and economically. However, the application of DOE by chemical engineers in industry is quite limited due to the lack of statistical knowledge in experimental design techniques [23]. There are some examples concerning engineering students with statistical design of experiments by active learning projects [24].

Through the use of real case studies our master chemical engineering students are encouraged to use experimentation (DOE) by simulation as an important part of the learning process. The procedure for integrating design of experiments and simulation with Aspen HYSYS to improve distillation systems is illustrated in Fig.2. The starting point in order to design and optimize a distillation system using statistical tools and modular simulators consists in choosing a real case study, a distillation system to further optimize. After the selection of a case study from the literature the students need to implement and simulate the distillation system, in order to establish the initial conditions which are the conditions described in the literature (see Fig.2).

By using this type of tools students learn to be conscious of what information they already know about the problem in hands, what information they need to know to solve the problem and the strategies to use. The articulation of such thoughts helps students become more effective problem solvers and self-directed learners [25]. 

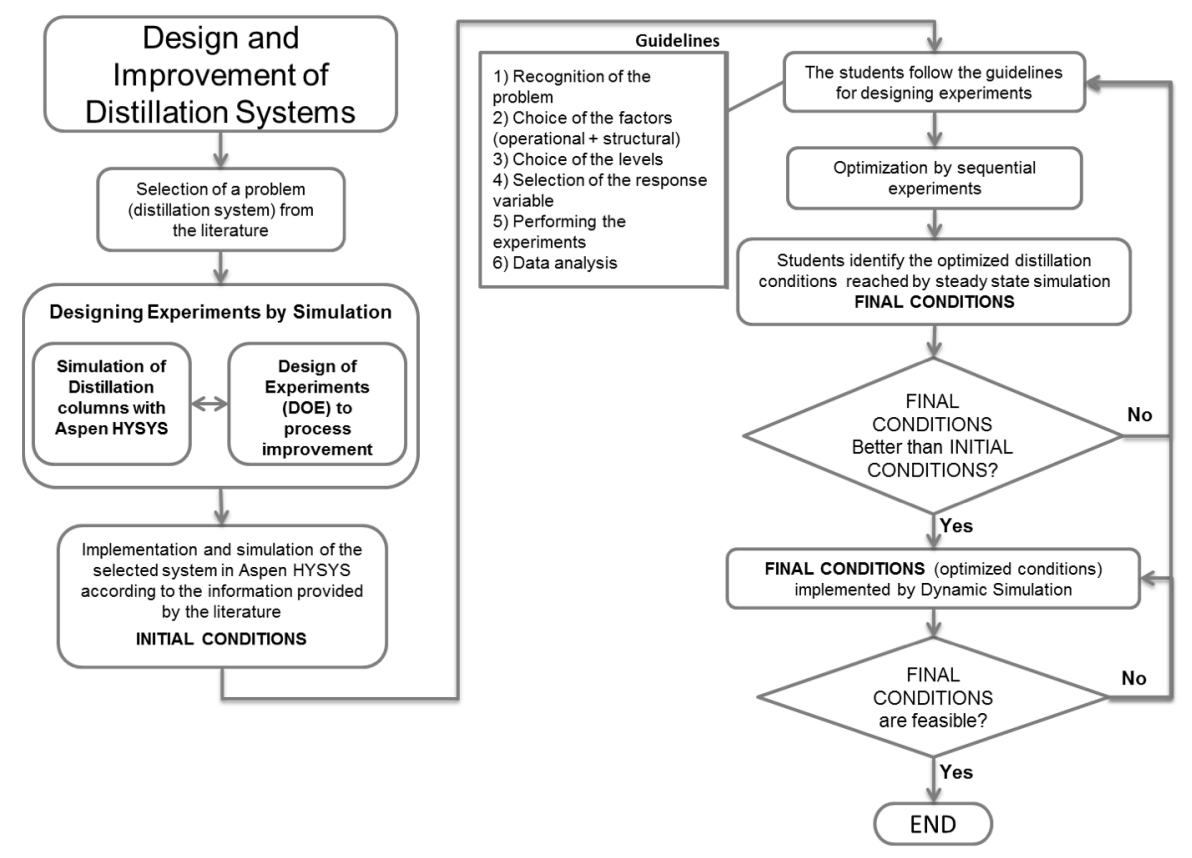

Fig. 2. Flowsheet for the design and improvement of distillation Systems integrating Aspen HYSYS and DOE.

\section{Design and improvement of distillation systems - two projects from a Portuguese chemical engineering master course}

The selected problems are based on distillation since this remains the primary separation process used in industry for the separation of liquid mixtures. The challenge of both projects are to study alternatives in terms of configuration and design of distillation structures to improve the efficiency of the process and reduce energy consumption which is of growing concern nowadays.

Two different case studies were given to the students involving distillation processes with thermal coupling. Despite the high potential of the distillation process with thermal coupling economic benefits, a lack of reliable design methods has contributed for the low number of commercial solutions [26].

Therefore, it is still a challenging task for engineers to define near optimal design conditions for those systems in a simple and efficient manner in the initial stage of the design procedure. Several distinct configurations of thermal coupling systems can be implemented in commercial process simulators, but the challenge is to find optimal or near optimal solutions for the problem due to the large number of design variables of those systems which lead to tedious iterative simulations in order to find a proper structure. 


\subsection{Project I}

This case consists of studying the optimal conditions for the fully thermally coupled distillation columns, FTCDC, through process simulation with Aspen HYSYS and statistical experimental design to separate a mixture of 2-methylpropan-1-ol, butan-1-ol and butan-2-ol. To implement the initial conditions, the student started the design using the methodology proposed by Triantafyllou and Smith [27], using the preliminary design equations based on short-cut Fenske-Underwood-GillilandKirkbride method (FUGK) to find the initial configuration for the Petlyuk column. The design was implemented in Aspen HYSYS v7.3 and for the computation of the thermodynamic properties it was used the UNIQUAC model with the binary parameters from the Aspen HYSYS database. A prefractionator followed by a product column characterizes this system. The first step of the design procedure applied the short-cut distillation method (FUGK) to obtain a first approximation for the Petlyuk structure. In this step, the student was able to identify the values, work levels, for the main variables of this system and implemented a new structure consisting on an absorber, which corresponds to the prefractionator, and a distillation column. The student followed the guidelines for designing the experiments and identified the main design factors which were aggregated into two types: six structural factors and two operational factors. In the present case the student identified a total of 8 factors and concluded that would need a total of 256 simulations (experiments) in order to perform all the combinations which would be rather time consuming. In order to reduce the number of simulations and assuming the sparsity of effects principle a fractional factorial design was selected to obtain information on the main effects and low order interactions. The fractional factorial chosen was $2_{\mathrm{IV}}{ }^{8-4}$. This design only requires 16 experiments reducing considerably the number of runs required for a full factorial experiment. In order to interpret the results of fractional factorial designs it is necessary to take into account the alias relationships [28]. The response variable selected was the total cost obtained with the Aspen Economic Evaluation using the default definition [29]. With this tool, it is possible to obtain a rapid estimation of the capital and operational cost of each run. After performing the 16 experiments, the effects were estimated and a normal probability plot of the effects was built, in order to graphically judge the relevance of the factors and interactions. After ANOVA computation the student concluded that a total of 4 factors and 3 interactions affect significantly the total cost (response variable), a result tested with ANOVA. After performing the fractional factorial design for process characterization the next step was the process optimization in order to find the set of conditions that result in the lowest total cost. In order to optimize the student decided to use the method of steepest descent, which is a procedure for moving sequentially along the path of steepest descent that is in the direction of the minimization of the response. A second cycle of simulations were performed varying the factors considered significant. The experiments were conducted along the path of steepest descent. After that, a third designed experiment was performed in order to further move along the path of steepest descent. After the whole process of optimization done sequentially, the final conditions of all factors (structural and operational variables) in order to minimize the total cost were deter- 
mined. The use of these conditions in the Petlyuk column allows a reduction of the total cost of $9.6 \%$ relative to the initial conditions.

After performing the statistical designed experiments, the student was able to verify that the final conditions were better than the initial ones and so the next step consisted in testing the final conditions by dynamic simulation using the Aspen HYSYS in dynamic mode. This type of system is more complex than a traditional distillation column with more degrees of freedom. Taking in consideration the control objective and previous work done by Wolf and Skogestad [30] and Hwang et al. [31] it was chosen a LV configuration with SISO feedback control loops, adapted from the LV configuration used in traditional distillation columns. The control of the FTCDC system is more complex than in a traditional distillation column and the results obtained showed that the response time of the system is higher when compared with a system of two columns for the same separation, but even so possible to control. The FTCDC control can be improved using model predictive control strategies. The student concluded that the combination of statistical tools like DOE proved to be very useful in the simulation of multicomponent separation reducing considerably the number of simulation runs to achieve an optimized solution for a particular problem. In the case of this Petlyuk system a reduction of the total cost estimation of almost $10 \%$ was obtained with a reduced number of runs. The dynamic simulation of the optimized Petlyuk column showed the possibility of operation of this system, but it is still necessary to implement new control strategies to overcome the high response time observed with the use of model predictive control as strategy to improve the performance of these systems. Details of the study can be found in [32].

\subsection{Project II}

This case concerns the design and optimization of an azeotropic distillation system with thermal coupling. A bioethanol dehydration process, requiring a significant amount of energy to overcome the azeotrope behaviour of ethanol-water mixture, was selected from the literature. The distillation system reported in the literature illustrates a new alternative process of intensification based on a dividing wall column (DWC) with energy saving and less equipment units when compared to the conventional azeotropic by extractive distillation configurations [33]. The student implemented by simulation with Aspen HYSYS v7.3 software this process consisting of a mixture of water and ethanol. The feed composition of ethanol is slightly lower than that of the composition of the well-known binary azeotrope formed between constituents. It was used n-pentane as mass agent to break the azeotrope obtaining a heterogeneous azeotropic distillation scheme. The system consists of two columns connected in reverse order. In the main column it takes place the azeotropic distillation, yielding the ternary azeotrope as a distillate and ethanol as a residue. The side stripper performs the recovery of the mass agent on the distillate stream, which is recirculated to the main column. The residue stream from this column consists essentially of water. Both columns are joined by two streams, vapour and liquid in a thermally coupled distillation columns with side stripper (TCDC-SS) system. 
After establishing the initial conditions of the system the student selected by hands on approach the factors to optimize namely structural and operational factors and the response variable, using the guidelines for designing experiments. Twelve factors were identified in order to optimize the system consisting of seven structural factors and five operational factors. With 12 factors, the number of runs required to perform a full factorial design $\left(2^{12}\right)$ would require 4096 simulations, which would be unfeasible, due to the huge time required. However, the objective was to obtain information on the main effects and low order interactions and so a fractional factorial design would serve the purpose with the benefit of the reduced number of simulations to perform. Thus, a fractional factorial design $2{ }_{\mathrm{IV}}{ }^{(12-7)}$ was adopted, obtaining a design matrix of 32 of experiments by simulation without replication [34].

With this design the 32 simulations were performed making changes in the structural and operating variables and the corresponding changes in the response variable (i.e. the respective total (investment plus operative) annualized costs for the several experiments, obtained through the Aspen Economic Evaluation.

To analyse the data from the fractional factorial design the analysis of variance (ANOVA) was used. Optimization was performed in a sequential procedure with the method of steepest descent moving sequentially along the direction of the maximum decrease in the response.

Fig. 3 presents the total cost starting with the base case (i.e. initial conditions), the case study reported in the literature, by implementation of the conditions of the work [33] followed by the sequential designed experiments achieving a cost reduction of $32.1 \%$. The student was able to conclude the benefits of Integrating Design of Experiments and Simulation with Aspen HYSYS in order to improve Distillation Systems and with this procedure it was possible to reach a huge reduction of costs for the separation process of ethanol water mixture through azeotropic distillation.

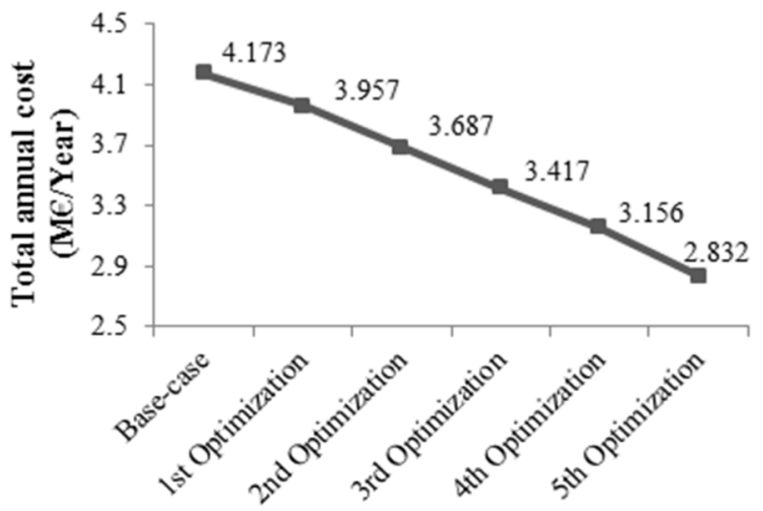

Fig. 3. Total annual cost versus optimization process for the azeotrope distillation system.

The work levels of the improved system obtained by simulation in steady state were then tested by dynamic simulation. The goal of dynamic simulation is to verify if the system meets the designed objectives ensuring the specification in terms of 
purity of the product of interest (ethanol). In order to make the transition from steady state to dynamic and perform the analysis of controllability it is required to perform some actions and changes concerning the process diagram created for the steady state and set an appropriate control strategy according to Aspen HYSYS - Dynamic Modelling Guide V.7.3. The control structure was defined and the applicable control loops introduced. After tuning the various controllers, it was possible to obtain a stabilized system. The student also analysed the overall behaviour of the system due to the introduction of disturbances. It was also possible to implement a control structure that allowed an adequate response in relation to the introduced disturbances, proving that the final conditions are feasible [35].

\section{$5 \quad$ Evaluation of the projects and impact on students learning}

\subsection{Evaluation of the projects}

Each final project was performed by one student according to the rules of the master project and each student presented a written report, which was evaluated by a jury and also an oral presentation in order to defend the project in a public presentation. The key elements that the students had to demonstrate in their master project include: a) Were the objectives clearly stated?; b) Was the problem clear and well defined?; c) Has the design, modelling and analysis been clearly understood?; d) Are the results technically and economically feasible?; e) Are the conclusions effective?; f) Was the content well organized?; g) Was there an appropriate use of engineering tools necessary to engineering practice?; h) Was the message clearly delivered?

Each written report was evaluated by a jury with respect to the content and quality of the project. The jury evaluated the extent to which the research is innovative (i.e. contribution to a concrete system design new or improved one, the creativity and independence of the student in the introduction of new or improved concepts), the application of the correct research and methodologies, the extent to which the research proposal has been met, the relevance of the project (i.e the applicability in practice, ability to put the research in context).

The independence and professional skills of the students were evaluated (e.g. independence, assimilation of feedback, communication skills, cooperation) as well as the students' attitude to reinforce individual development, the commitment and enthusiasm with the project and the reflection upon their own work.

Each student's oral presentation has also been evaluated by the corresponding examination panel concerning the ability to communicate effectively (e.g. if the message is coming across, if the student has a captivating way of presenting concerning verbal capabilities as well as posture), insight in subject matter and coherence between different parts of the project (i.e. knowledge concerning contemporary analytical, computational and experimental practices, know how in chemical process simulation software, and the skills in statistical experimental design, planning, conducting the experiments and the statistical analyses of the results). 
The two examples of master projects described provided the students an opportunity to demonstrate acquired competences and skills concerning design, analysis, and control of advanced chemical processes. This includes abilities in requirements such as:

a) Familiarity with statistics in real application environment;

b) Competences in experimental design, data collection and data analysis;

c) An ability to work professionally in chemical systems areas including the design analysis and improvement of such systems;

d) Skills in the use of computational tools and

e) Independent thinking, creativity and ability to tackle advanced chemical engineering problems in real contexts.

\subsection{Impact of the projects on students learning}

The methodology used in both projects had a great impact on both students especially due to the hands on approach in statistical experimental design techniques and optimization, and also to the use of process simulators. The work had a great impact on student's efforts to accomplish the tasks. According to students' opinions the methodology followed was very helpful in order to increase their ability to work independently. The students exhibited a good attitude during the progress meetings and revealed active reflection upon their own work. The work also had a great impact in raising the communication ability of the students because the students felt stress-free in reporting the progress on intermediate steps. The students found the methodology very useful as reported by the comments they made during the project and also during the discussion of the project. The comments were very positive and some of their remarks are summarized below:

"I found the use of statistical design of experiments very challenging because I had no previous experience on using these type of statistical tools during my course"

"I found the project very challenging mainly due to the objective of optimizing a system that was already published in literature and I was afraid that there was not much space in order to further improve the system, which came to be a wrong thought".

"The implementation of the system to optimize was useful and allowed to apply my Aspen HYSYS skills"

"I learn by hands on approach how to plan and perform the experiments and I think that DOE will be useful in my future profession"

"I learned to model dynamic processes and this is likely to have much interest in the future as an engineer".

"I found very challenging looking for the information needed in order to solve the problem in hands"

"I improved my skills in simulation with Aspen HYSYS concerning the conceptual design of distillation schemes for the separation of chemical mixtures"

The comments of the students were very informative and in line with the objectives of each project. The students found very enriching using statistical experimental design techniques along with simulation using Aspen HYSYS by hands on approach 
procedure and they were able to plan and perform the experiments using the right research and design methodologies.

\section{Conclusions}

This kind of inductive teaching and learning showed very enriching because it imposed more responsibility to the students for their own learning. In fact, students build their own thinking, discussed questions with the teachers and solved problems by an active learning process. The teachers guided the process without controlling the students' choices and that is an important issue to have into consideration. This is in accordance with de Graaff and Mierson [36] and Margetson [37] which refer that the role of the teacher is very challenging involving more than just subject knowledge. The students followed the orientations of the teachers but they were responsible for their decisions meaning that they decided how to implement the systems and the methods to use in order to optimize the systems. Students recognised the problem under study and were able to realize the complexity of the systems. The optimization of complex and real problems help them to develop content knowledge as well as problem solving, reasoning and self-assessment skills. The students realized that they were also acquiring the skills needed to be successful in the field because they had a clear picture of the role that chemical engineers may have in improving the performance of the processes and recognized the relevance of undertaking engineering activities in a way that contributes to sustainable development. Students also understood that computer software process simulation tools are essential for providing fast and, as much as possible, accurate solutions. Aspen HYSYS software for process simulation enabled simple and quick conceptual design of distillation structures in order to make separations of chemical mixtures being crucial in the design, analysis and evaluation of the processes. Both students found very enriching the fact of being able to identify the factors to optimize and select the response variable to measure and also to plan and develop the simulation runs and statistical analysis by themselves, evaluating and deciding which runs to perform in order to optimize the examples selected from the literature. The students found very motivational taking their own decisions concerning the procedure for moving sequentially along the direction of the costs minimization. The students also found very useful the knowledge they got in factorial and fractional factorial designs particularly the usefulness of these designs for screening the variables in the distillation system and determining those that are more important. They learned how to analyze the data from factorial designs and how to test the model adequacy for factorial designs.

The students felt the approach very useful to enrich their technical knowledge in relevant areas of chemical engineering increasing their expertise in tools which are widely-used across the industry to model steady-state or dynamic processes and to perform studies in order to optimize the systems. They also found that the work developed helped them to be conscious about the information they need to know to solve the problem in hands, about the strategies to use in order to optimize the sys- 
tems and above all allowed them to see the impact of the engineering solutions they reached.

From the teachers' perspective it was very important that students could learn by a hands on approach procedure how to improve a process with designed experiments. The simulation of distillation systems with tools, like Aspen HYSYS that the students already knew from some curricular units taught in the course was a starting point to deal with statistical experimental design in order to optimize a system published in the literature.

The use of such tools associated with real cases allows students to see how useful statistics can be in their late careers in industry. The students improve their skills in problem analysis being able to convert an engineering problem into statistical terms from which appropriate solutions can be chosen.

From the teachers' viewpoint it is advantageous to integrate DOE with process simulation tools because it can overcome some issues related with available financial resources to explain and training this type of statistical techniques. Globally the methodology was very helpful to promote self-directed learning and the adoption of a deep approach to learning where the students assumed a high level of responsibility for their own learning.

This kind of projects allows students to contact with industrially relevant separation processes and were a good opportunity that the students fully used to act as engineers applying their scientific and technical knowledge to successfully optimize distillation systems.

Due to the success of this type of procedure it is worth to apply to other type of systems and also to other type of chemical operations meaning that the work will have a potential impact on a wider public and can be placed in a wider educational context.

\section{$7 \quad$ References}

[1] R. Clift, R. (2006). Sustainable development and its implications for chemical engineering. Chem. Eng. Sci., 61(13): 4179-4187 https://doi.org/10.1016/j.ces.2005.10.017

[2] Glassey, J. and Haile, S. (2012). Sustainability in chemical engineering curriculum. Int. J. Sustain. High. Educ., 13(4): 354-364 https://doi.org/10.1108/14676371211262308

[3] Henley, E.J., Seader, J.D. and Roper, D.K. (2011). Separation process principles, 3rd ed. Wiley

[4] Speight, J.G. (2014). The Chemistry and Technology of Petroleum, 5th ed. CRC Press

[5] Kiss, A.A. (2014). Distillation technology - still young and full of breakthrough opportunities. J. Chem. Technol. Biotechnol., 89(4): 479-498 https://doi.org/10.1002/jctb.4262

[6] Kiss, A.A. (2013). Advanced Distillation Technologies: Design, Control and Applications. Chichester, UK: John Wiley \& Sons, Ltd https://doi.org/10.1002/9781118543702

[7] ABET, Accreditation board of engineering and technology. (2016-2017). Criteria for accrediting engineering programs. http://www.abet.org/wp-content/uploads/2015/10/E00116-17-EAC-Criteria-10-20-15.pdf

[8] Michael, J. (2006). Where's the evidence that active learning works? Adv. Physiol. Educ., 30(4): 159-67 https://doi.org/10.1152/advan.00053.2006

[9] Lambert, N.M. and McCombs, B.L. (1998). How students learn: reforming schools through learner-centered education. Washington DC.: American Psychological Association https://doi.org/10.1037/10258-000 
Paper-Designing Solutions by a Student Centred Approach: Integration of Chemical Process Simula...

[10] Bransford, D., Brown, A.L., Cocking, R.R., Donovan, M.S. and Pellegrino, J.W. (1999). How People Learn - Brain, Mind, Experience, and School. Expanded Ed. Washington DC: National Academy Press

[11] Handelsman, J., Ebert-May, D., Beichner, R., Bruns, P., Chang, A., Dehaan, R., Gentile, J., Lauffer, S., Stewart, J., Tilghman, S.M. and Wood, W.B. (2004). Scientific Teaching. Source Sci. New Ser., 304(23): 521-522

[12] Cooper, J.L., MacGregor, J., Smith, K. and Robinson P. (2000). Implementing small-group instruction: Insights from successful practitioners. New Dir. Teach. Learn., 2000(81): 6376 https://doi.org/10.1002/t1.8105

[13] Felder, R.M. and Brent, R. (2003). Designing and teaching courses to satisfy Engineering Criteria 2000. J. Eng. Educ., 92(1): 7-25 Felder and Brent (2003)

[14] Bloom, B.S. and Krathwohl, D. R. (1956). Taxonomy of Educational Objectives: The Classification of Educational Goals, by a committee of college and university examiners. Handbook I: Cognitive Domain. NY, NY: Longmans, Green

[15] Anderson, L. W., Krathwohl, D. R., Airasian, P. W., Cruikshank, K. A., Mayer, R. E., Pintrich, P. R., Raths, J. and Wittrock, M. C. (2001). A Taxonomy for Learning, Teaching, and Assessing: A Revision of Bloom's Taxonomy of Educational Objectives. Allyn \& Bacon. Boston, MA (Pearson Education Group)

[16] Glassey, J., Novakovic, K. and Parr, M. (2013). Enquiry based learning in chemical engineering curriculum supported by computer aided delivery. Educ. Chem. Eng., 8(3): e87e93 https://doi.org/10.1016/j.ece.2013.06.003

[17] Bradstreet, T.E. (1996). Teaching Introductory Statistics Courses so That Nonstatisticians Experience Statistical Reasoning. Am. Stat., 50(1): 69-78

[18] Garfield, J.B. (1995). Respondent: 'How should we be teaching statistics? Am. Stat., 49: 18-20 https://doi.org/10.1080/00031305.1995.10476105

[19] Moore, D.S. (1997). New Pedagogy and New Content: The Case of Statistics. Int. Stat. Rev., 65(2): 123 https://doi.org/10.1111/j.1751-5823.1997.tb00390.x

[20] Vosniadou, S. (2003). Exploring the relationships between conceptual change and intentional learning, in Intentional Conceptual Change, Sinatra, G.M. and Pintrich, P.R. (Eds.). L. Erlbaum, pp. 377-406

[21] Garfield, J. (2002). The challenge of developing statistical reasoning. J. Stat. Educ., 10(3): $1-10$

[22] Luyben, W.L. (2006). Distillation Design and Control Using AspenTM Simulation. Hoboken, NJ, USA: John Wiley \& Sons, Inc. https://doi.org/10.1002/0471785253

[23] Tanco, M., Viles, E., Jesus Álvarez, M. and Ilzarbe, L. (2010). Why is not design of experiments widely used by engineers in Europe? J. Appl. Stat., 37(12): 1961-1977 https://doi.org/10.1080/02664760903207308

[24] I. M. João and J. M. Silva, "Student engagement with statistical design of experiments by active learning projects," in 2nd International Conference on Higher Education Advances, HEAd'16, 2016, pp. 203-210.

[25] Gijselaers, W.H. (1996). Connecting problem-based practices with educational theory. New Dir. Teach. Learn., 1996(68): 13-21 https://doi.org/10.1002/tt.37219966805

[26] Caballero, J.A. and Grossmann, I.E. (2006). Structural considerations and modelling in the synthesis of heat-integrated-thermally coupled distillation sequences. Ind. Eng. Chem. Res., 45(25): 8454-8474 https://doi.org/10.1021/ie060030w

[27] Triantafyllou, C. and Smith, R. (1992). The design and optimisation of fully thermally coupled distillation columns: Process design. Chem. Eng. Res. Des., 70: 118-132

[28] Montgomery, D.C. (2012). Design and Analysis of Experiments, 8th ed. Hoboken, NJ: Wiley

[29] Towler, G.P. and Sinnott, R.K. (2008). Chemical engineering design: principles, practice and economics of plant and process design. Burlington, MA: Elsevier 
Paper-Designing Solutions by a Student Centred Approach: Integration of Chemical Process Simula...

[30] Wolff, E. and Skogestad, S. (1995). Operation of integrated three-product (Petlyuk) distillation columns. Ind. Eng. Chem. Res., 34(1962): 2094-2103

[31] Hwang, K.S., Kim, B.C. and Kim, Y.H. (2011). Design and Control of a Fully Thermally Coupled Distillation Column Modified from a Conventional System. Chem. Eng. Technol., 34(2): 273-281 https://doi.org/10.1002/ceat.200900483

[32] Florindo, S.S., João, I.M. and Silva, J.M. (2014). Study of Energy Efficient Distillation Columns Usage for Multicomponent Separations through Process Simulation and Statistical Methods, in 24th European Symposium on Computer Aided Process Engineering, vol. 33, Klemes, J.J., Varbanov, P.S. and Liew, P.Y. (Eds.), pp. 145-150

[33] Kiss, A.A. and Suszwalak, D.J.P.C. (2012). Enhanced bioethanol dehydration by extractive and azeotropic distillation in dividing-wall columns. Sep. Purif. Technol., 86: 70-78 https://doi.org/10.1016/j.seppur.2011.10.022

[34] Montgomery, D. (1999). Introduction to Statistical Quality Control, 6th ed. New York, Wiley

[35] Mendonça, M.V., João, I.M. and Silva, J.M. (2014). Azeotropic Distillation Systems: Design and Optimization through simulation with Aspen HYSYS combined with Design of Experiments, in 12th International Chemical and Biological Engineering Conference, Porto, pp. 14-21

[36] De Graaff, E. and Mierson, S. (2005). The dance of educational innovation. Teach. High. Educ., 10(1): 117-121 https://doi.org/10.1080/1356251042000252426

[37] Margetson, D. (1994). Current educational reform and the significance of problem-based learning. Stud. High. Educ., 19(1): 5-19 https://doi.org/10.1080/03075079412331382103

\section{Authors}

Isabel Maria João is a Professor at the Polytechnic Institute of Lisbon, School of Engineering (ISEL), at the Chemical Engineering Department since 2000. She has 9 years of Industrial experience in a Plastic industry where she was the chief of the laboratory of I\&D and quality control and improvement. Isabel received her $\mathrm{PhD}$ degree in Industrial Engineering and Management from IST/UTL and a Master degree in Management and Quality of Materials from FCT/UNL and she also holds a graduation in Chemical Engineering from IST/UTL. She is a researcher at the Centre for Management Studies of IST (CEG-IST) and her areas of interest include Innovative Product and Process Design, Quality Management and Decision Analysis and Information Systems.

João Miguel Silva is a Coordinator Professor at the Polytechnic Institute of Lisbon, School of Engineering (ISEL) and the Head of the Chemical Engineering Department since 2010. He is member of the research center CQE - Centro de Química Estrutural in the Heterogeneous Catalysis and Catalytic Processes (CATHPRO) group at IST. João received his $\mathrm{PhD}$ degree in Chemical Engineering in 1994 from IST/UTL and is co-author of over 50 articles in peer-review journals. His areas of interest include Innovative Product and Process Design, Process Simulation and Heterogeneous Catalysis, specifically with zeolites.

Article submitted 22 February 2017. Published as resubmitted by the authors 27 April 2017. 